Simona Škrabec

Barcelona

\title{
LES POSSIBILITATS PERDUDES: PERE CALDERS, ENTRE LA RATLLA I EL DESIG
}

En un dels capítols del llibre Els límits de la interpretació d'Umberto Eco trobem escrita sense cap èmfasi especial una observació que resulta essencial per acostar-nos a la narració Entre la ratlla i el desig de Pere Calders (Eco, 1990: 279-305). Eco sosté que per dir una banalitat tan òbvia com, per exemple, que mai no trobarem l'ànec Donald caminant pel Passeig de Gràcia, no necessitem ajuda de cap aparell teòric. Aquesta observació delimita amb un tall precís i net -encara que poc convencional- l'objecte de l'anàlisi que ens interessa: volem parlar d'un text. Només del text. La caseta de fusta, com l'objecte principal al voltant del qual gira tot el conte de Pere Calders, està feta de paraules i aquestes són fruits d'una convenció, d'estratègies emprades per construir el discurs. Per això dividiré l'anàlisi del conte La ratlla i el desig en dos capítols.

Primer veurem que el món narratiu està construït per unes paraules fràgils com un vas d'argila i ens encararem a la qüestió de quina importància tenen en relació amb la realitat. La segona part de l'anàlisi es centrarà en les estratègies discursives, en la seducció del text: Què és allò que el text ens vol fer creure? Com l'ha de llegir el Lector Model? Sabent quina és l'estructura profunda d'aquest conte podrem decidir en quin sentit l'agrimensor no és capaç de comunicar-se amb el seu entorn i per què tots els seus intents de viure una vida feliç fracassen. Aquest personatge narratiu, com tants d'altres, viu en un món handicapat i el que intentarem demostrar és que d'aquí prové tota la seva tragèdia.

Finalment haurem de reconèixer que aquest viatjant se'ns ha ficat sota la pell per recordar-nos com també nostra vida flueix sense retorn. El nostre propi passat, per molt extraordinari que fos, queda segellat i inaccessible. I encara que hi poguéssim tornar, quines garanties tindríem de saber fer-ho millor? Les possibilitats fantàstiques teixides per Pere Calders no ens obren cap camí de fugida, sinó que més aviat ens demostren com no existeix cap compensació per a les limitacions que ens determinen com a homes.

\section{Les paraules d'argila}

No olvidar que un personaje literario consiste en las palabras que lo describen (Bioy Casares, 1994).

El conte de Calders és una narració sobre un viatge amb autobús durant el qual un home explica als companys de viatge les peripècies de la seva vida anterior. Tot el que sabem, ho sabem per la narració que observa els esdeveniments des d'una perspectiva històrica. Perquè això no passi per alt a cap lector, l'autor trenca el teixit de la narració i dedica una observació directa als possibles lectors. L'observació està posada entre parèntesis i funciona realment com un apart en una representació teatral, com allò que el personatge que parla a dalt de l'escenari ho dedica no als seus companys de professió que s'esforcen a recrear una història, sinó al públic, perquè s'assabenti de coses que han de quedar desconegudes per a la resta de personatges. Vegem-la en el seu context: 
- Per què? -em va preguntar. I afegí-: Fa més de cinc anys que m'hauria d'haver mort, i sé totes les històries. Què hi podríem guanyar?

-No ho sé. Potser un consell.. -vaig dir-li.

(Això era fals, i la hipocresia, com sempre que en faig ús, m’envermellí les galtes. En realitat, el que cercava era referir aquella cosa extraordinària, com ara) (Calders, 1983: 23).

L'observació trenca la il-lusió que ens permetria endinsar-se en el món narratiu i prendre els personatges com si fossin «reals». Aquesta petita observació, adreçada a algú que està fora del text, pressuposa l'existència d'algú que llegirà la història. O si voleu, instaura amb una força especial un Lector Model, disposat a llegir tot allò que el narrador explica en una conversa amb els companys de viatge en autobús i extrapolar d'aquesta narració el que va passar. La petita observació pertany al món de referència en el qual el subjecte seria aquell jo de l'agrimensor que com ara explica el seu viatge amb autobús a la vall d'Àrea. Aquest seria el primer nivell que emmarca els límits del text, al seu interior, però, podem observar una estratificació més rica.

El lector té la impressió que està davant d'una única història. Difícilment dubtarà que no sigui així perquè la unitat del relat està garantida amb un argument que mai posem en dubte: la identitat personal. El narrador en primera persona conta la història en la qual el protagonista és ell mateix. I això vol dir que pot legitimar el seu relat amb una fórmula que ens és ben familiar: «Ho he vist amb els meus propis ulls». En el món en què vivim ens acostumem a creure qualsevol cosa que ve autentificada amb aquest segell tot i que sabem que fora d'allò que enfoquen les càmeres -aquesta pròtesi amb la qual els nostres ulls poden arribar als racons més remots de l'univers- queden moltes coses, i que prenent unes altres imatges o simplement disposant-les en un ordre diferent, la història que conten seria diferent. Això equival a dir que la realitat també és una construcció.

Si pretenem analitzar una obra literària del nostre temps hem d'ésser conscients que per algú que habita a primers del segle vint-i-u la noció de la realitat objectiva és molt problemàtica. És un fet, la filosofia moderna ha aconseguit anul-lar la seguretat de saber què és la realitat, com a mínim a partir de la frase històrica del seu gran precursor Charles S. Peirce: L'home és un signe. ${ }^{1}$ Això mateix expressa també la frase the fiction is that reality exists, que no cal recordar només com el títol de l'article de Siegfried J. Schmidt (1997: 207-238), sinó que també ha de ser una de les idees bàsiques que hem de tenir presents per enfrontar-nos amb els móns ficcionals que han començat, com a mínim a partir del segle XX, a qüestionar sistemàticament la nostra fe cega en tot allò que els sentits dels quals disposem fan que ens ho creguem real. D'aquesta manera la literatura és el mirall d'una determinada concepció del món. Si jo crec que la meva percepció del món crea una imatge subjectiva que jo interpreto com a realitat, llavors escric llibres que agraden als constructivistes, però si jo mai m'he preguntat sobre els mecanismes que guien el meu coneixement, escric llibres que s'esforcen a reproduir la realitat tan fidelment com sigui possible i agraden als crítics que només poden apreciar una literatura «realista».

${ }^{1}$ Peirce, 1987: 86. «No existe ningún elemento en la consciencia del hombre que no tenga algo que le corresponda en la palabra: todo pensamiento es un signo, la vida es una corriente de pensamiento; esto prueba que el hombre es un signo». 
L'home, igual que tots els sistemes vius, forma part d'un continu procés de socialització. Per això la cognició individual està forçada a adoptar un determinat model de món, imposat per les estructures de poder. En el cas de l'home aquesta estructura que el guia sobre com ha d'organitzar els seus senyals sensorials en un mapa de realitat coherent és la llengua. La llengua, en tant que sistema que fem servir per organitzar la realitat, és allò que determina les fronteres del nostre món.

Per això és difícil dir quin tipus de cases fetes de paraules és menys ficcional que l'altre. Fins i tot de l'existència de les cases que sorgeixen d'un reportatge periodístic se'n podria dubtar. Per molt escrupulós que sigui el periodista amb la seva feina no pot evitar de construir el seu text a través de la selecció de la realitat. I la selecció d'un determinat tros de realitat significa interpretació, una visió subjectiva. ${ }^{2}$ Només en el cas que algú es pogués imaginar una cosa real en tots els seus infinits detalls es podria dir que té una imatge seva. Jorge Luis Borges en el seu conte Funes el memorioso ens recorda com de dolorosa seria aquesta possibilitat hipotètica (Borges, 1989: 485-484). Si això és així, és evident que ningú no té una imatge vertadera del camí fins a la seva oficina o de qualsevol altra cosa real. La qüestió es complica encara més en un cas com és el que trobem en el conte de Pere Calders que parla sobre fenòmens no gens versemblants.

Però no és només la impossibilitat d'anàlisi que veda als homes percebre totes les dimensions del món. Encara més greu que no poder veure un arbre amb totes i cadascuna de les fulles que formen la seva capçada és que no podem coincidir en la manera com ens imaginem un arbre. La imatge de l'arbre que evoca la paraula no correspon a una síntesi de tots els arbres que mai hagin crescut en algun lloc. Les últimes conseqüències filosòfiques d'aquesta incapacitat humana de conèixer les coses tal com són ens les descobreix Charles S. Peirce dient que «la imagen de un hombre debe ser de un blanco, un negro o un mulato; de un hombre derecho o uno encorvado; de uno alto o bajo o de mediana estatura» (Peirce, 1987: 79).

El concepte de la realitat en la literatura és un terreny molt relliscós. Quins perills ens hi esperen ho podem il-lustrar amb l'anàlisi d'un conte tan emblemàtic com és Die Verwandlung de Franz Kafka feta per Ljubomir Doležel. Val la pena parar-s'hi un moment, si més no, pel sol fet que la narració La ratlla $i$ el desig és la més «kafkiana» que ha escrit Pere Calders. ${ }^{3}$ Doležel sosté que el món d'aquesta narració de Kafka és un món híbrid de manera que en el cas de Gregor Samsa no sabem si és un home amb el cos de cuca o una cuca que té records i consciència d'home. ${ }^{4}$ Però dient això, Doležel s'oblida que el llenguatge, i sobretot el llenguatge poètic, s'escapa del domini del sentit literal. I en poques obres trobaríem una metàfora tan ben elaborada com precisament en el conte de Kafka que no és altra cosa que una immensa al-alegoria sobre un jove escriptor que a causa de la seva afició a l'escriptura és tractat per la seva família com un insecte.

\footnotetext{
2 Albaladejo, 1996: 297-304. Exemple d'un investigador que ni tan sols es planteja aquesta reflexió. La seva «ley de máximos semánticos» creu que la classe de textos tipus 1 està formada "por instrucciones que corresponden a reglas propias de realidad efectiva, por lo que en tal caso lo que hace es adoptar una sección de la propia realidad efectiva».

${ }^{3}$ L'agrimensor té un ofici massa poc freqüent per no tenir res a veure amb el protagonista de la novel.la Der Prozeß. La següent cita: «El viatjant digué que era difícil: un cosí seu al qual havia passat una cosa que, sense ser igual, també creava dificultats, la família, després de reunir-se, l'havia enviat a Amèrica» (p. 31) fa pensar immediatament en el començament d'una altra novel-la de Kafka, Der Verscholene (o Amerika, nom amb el qual també és coneguda). Karl Roßmann, el protagonista, que té disset anys, és enviat a Amèrica perquè va fer un fill a una serventa.

${ }^{4}$ Doležel, 1997: 82. Nota a peu de pàgina número 18.
} 
Gregor Samsa no és cap monstre. Contra aquest parany de buscar el sentit literal en el llenguatge metafòric també va alertar Umberto Eco en el seu llibre Els límits de la interpretació (Eco, 1991: 284-288). L'exemple amb el qual il-lustra la seva advertència parla d'Àquiles a qui Homer compara amb un lleó, però això no vol dir que tingui característiques d'un felis leo, simplement vol dir que és valent com ho podria ser un lleó. Si això és així, llavors no té gaire sentit buscar a quin insecte s'assemblaria Gregor Samsa un cop transformat.

Però tot $\mathrm{i}$ aquestes reflexions ens hem de fer la pregunta quina caseta de fusta té prioritat davant l'altra, la que no s'ha mogut de la vall idíl-lica o aquella que va néixer com el producte d'un desig? Una resposta la podríem trobar en les paraules d'un altre gran escriptor del nostre temps, Italo Calvino, extretes del seu llibre Les ciutats invisibles que també parla, igual que el conte de Pere Calders, sobre els fenòmens arquitectònics que són productes de la fantasia. En el seu relat sobre «Les ciutat i el desig» (Calvino, 1985: 35-36) Marco Polo descobreix la gran meravella que s'amaga a la ciutat de Fedora:

\begin{abstract}
Al mig de Fedora [...] hi ha un palau de metall amb una esfera de vidre a cada cambra. Mirant endins de cada esfera es veu una ciutat blava que és el model d'una altra Fedora. Són les formes que hauria pogut prendre la ciutat si, per una raó o per l'altra, no hagués arribat a ser tal com la veiem avui. En cada època algú, mirant Fedora tal com era, va imaginar una manera de fer la ciutat ideal; però mentre construïa el seu model en miniatura, Fedora ja no era la mateixa d'abans i allò que fins ahir havia estat un dels seus possibles futurs ara només era una joguina dins una esfera de vidre.
\end{abstract}

Allò que ens ha d'interessar més en aquest informe de Marco Polo és l'argument que ens pot servir per no caure en la trampa i intentar parlar sobre dues classes de literatura, una més fidel a la realitat que una altra. Això ens confirma que per als homes en minúscula -com anomena Pere Calders aquelles persones que encara troben temps de llegir un llibre i que creuen que «el volar sense aparells és cosa corrent, de cada dia» (Calders, 1983: 15) - el mapa del món seria com aquell que demana Marco Polo al Gran Kahn:

El mapa del teu imperi, oh Gran Kahn, ha de tenir lloc per a la gran Fedora de pedra i també per a les petites Fedores en les esferes de vidre. No perquè totes siguin igualment reals, sinó perquè totes són només suposades. Una amaga allò que s'accepta com a necessari mentre encara no ho és; les altres, allò que s’imagina com a possible i un minut després ja no ho és.

Quan un relat porta el segell de la realitat no ens preguntem com està construït. No veiem el paper sobre el qual està impresa la foto (Martínez-Bonati, 1992: 96-98), sinó només la foto, o més ben dit, l'espai tridimensional que s'obre a través de la foto. Heus aquí la principal característica de l'art anomenat realista. La reproducció fidel de la realitat no vol dir altra cosa que ser capaç d'amagar tots els vestigis de la bastida, necessària per a aconseguir l'efecte desitjat. L'art sovint es proposa un objectiu més complicat, vol que ens adonem del paper fotosensible. L'artista vol a més a més que percebem que la distància efectiva entre el cap d'una persona i la lluna són només uns pocs mil·límetres i no els quilòmetres que percep el nostre ull, acostumat a aquest engany.

L'estructura de relats encaixats en el conte de Pere Calders té sens dubte com a objectiu recordar-nos que estem davant la ficció, de no permetre'ns una identificació fàcil. Però hi ha més coses que podem descobrir perfilant l'altra diferència important entre la 
història i l'art. Construint els éssers que viuen en el món real, qualsevol informació que rebem sobre un d'ells serveix per engreixar una mica més la nostra concepció que tenim d'ell. Totes les informacions que rebem, per exemple, sobre el Napoleó històric, van a parar al mateix sac i com més ple, millor (Martínez-Bonati, 1992: 91-111).

El narrador en primera persona en el conte de Calders ens sedueix perquè fem el que estem acostumats a fer en la vida quotidiana: posar totes les informacions sobre l'agrimensor en el mateix sac i d'elles extrapolar el concepte d'una persona psicològicament coherent que ha viscut totes les hores que han passat des de la seva primera arribada a vall d'Àrea fins al final del viatge d'autobús. D'aquesta manera construïm la imatge mental de l'agrimensor i, si tinguéssim un microscopi prou potent, veuríem el color dels seus mitjons o sabríem què li ha fet per sopar la dona en aquella casa en la qual es va negar a entrar per por que tot fos només un miratge. Però tot i que aconseguíssim omplir tots aquests forats indefinits el text no seria menys fictici.

Imaginem-nos una pel-lícula basada en aquest conte: la càmera hauria d'omplir forçosament totes aquestes llacunes que el text pot deixar indefinides. Però sabent que els cabells de la dona eren ondulats o bé llisos, veient la forma de la teulada o el nombre d'arbres que creixen davant la casa la història encara ens semblaria igual d'inversemblant, o no?

Sembla que l'estructura del conte de Calders -amb el seu narrador en primera persona que va recreant en el transcurs del relat allò que ell considera el seu passat- ens vulgui ensenyar el funcionament del procés de construcció de la realitat. Els sistemes vius no tenen capacitat de conèixer la realitat ontològica «objectiva». Un sistema viu pot percebre només els senyals sensorials produïts pel propi sistema que a continuació ha d'interpretar. Això vol dir que l'objecte no és més que el resultat d'alguns senyals sensorials organitzats en la ment. Un observador no pot conèixer l'objecte tal com és, l'únic que pot fer és descriure's l'objecte a ell mateix. La cognició està restringida al subjecte i depèn del subjecte. No hi ha cap possibilitat de percebre o descriure una realitat d'existència independent.

\section{Els paletes i manobres del discurs}

Vosaltres ja creieu en el nostre món actual. Només us demano que cregueu en més coses d'aquest gènere. ${ }^{5}$

El conte La ratlla i el desig ens l'explica un narrador. Aquest narrador, agrimensor de professió, i els lectors compartim el mateix nivell de la narració. El següent nivell s'organitza al voltant de l'agrimensor que viatja en autobús junt amb un home vell i un viatjant de comerç. A més a més, l'agrimensor intercala en la conversa amb ells una narració sobre ell mateix en un passat indefinit, remot. En aquest nivell ens trobem amb l'agrimensor com un personatge de la fàbula junt amb el gran terratinent, els treballadors i la seva estimada esposa. És en aquest nivell on trobem també la casa i el cavall com dos individus més, que participen en l'estructura d'aquest tercer món encaixat. Allò que unifica tots tres nivells és la narració en la primera persona.

I aquí hi ha la trampa que fa que nosaltres creiem trobar-nos davant el mateix agrimensor «ara», en l'autobús i en les propietats del gran terratinent. Però des del punt de vista estructural els tres móns són diferents i els individus que hi «viuen» només porten

\footnotetext{
${ }^{5}$ Lewis, D. K., citat per Eco, 1987: 278.
} 
els mateixos noms, tot i que són individus diferents: allò que els diferencia és sobretot el fet que habiten diferents zones temporals.

Hem dit que el narrador conta des del present els fets que han ocorregut en el passat i el protagonista dels quals ha estat ell mateix. La consciència de l'agrimensor unifica tot el relat, garanteix l'autenticitat i en una primera lectura superficial no hi ha res que des d'aquest punt de vista ens pogués semblar incongruent. De fet si no pensem en la manera com està construït el seu món és perquè el procediment que utilitza el narrador és el mateix que fem servir per construir la nostra identitat, composta de records, desigs, somnis.

Ara bé, hem de reconèixer que no hi ha res que pugui garantir que nosaltres sabem el que som i el que havíem estat. N'hi ha prou amb una mirada supèrflua a l'àlbum de fotos de la nostra infància per adonar-se com tot flueix i canvia. Encara que sé del cert que la criatura de cabells rossos de la foto sóc jo, no em puc posar a la seva pell, no puc recuperar els seus pensaments. El seu món per mi és irrecuperable. No puc tornar enrere, de la mateixa manera que no puc esborrar o cancel-lar res que hagi passat.

El problema de la identitat encara no ha estat resolt i per això també en el nostre temps és vàlid el pensament de Leibniz: «si tot l'univers fos diferent, jo seria un altre» (Eco, 1987: 263-286). Som com a monades que porten a dintre seu totes les possibilitats imaginables, però només en poden escollir i viure una de sola.

Allò que ens limita més com a éssers humans és la inaccessibilitat de nosaltres mateixos. No només perquè no podem tornar al passat i modificar-lo, sinó perquè fins i tot en el present no ens podem veure, no ens podem elevar i sortir a fora per veure'ns des d'una posició distant. Ningú no pot estar al mateix temps a dins i a fora.

El narrador en el conte La ratlla i el desig s'amaga sota la màscara d'un sol agrimensor, explicant-ho tot en primera persona. Aquesta perspectiva narrativa és una constant en la literatura de Pere Calders. La pluralitat d'encarnacions d'aquest narrador en primera persona va formant un mosaic i la diversitat de les peces que el formen fa impossible construir un sol home. La funció d'aquesta perspectiva narrativa és clara: el calidoscopi d'imatges subjectives no ens permet construir una sola veritat $i$ amb això ens recorda com és de fràgil allò que nosaltres creiem vertader i real en la vida que vivim.

Hi ha una altra cosa que ens pot afectar directament en la nostra condició de persones de carn i ossos. Escoltant el relat que l'agrimensor ens explica podem començar a sospitar que sovint la nostra visió del món actual és tan imperfecta com la dels personatges narratius. L'agrimensor narra els fets passats des del present, això vol dir que la seva perspectiva li permet conèixer el resultat de la seva vida: no s'ha d'enfrontar amb la incertesa del futur, sinó amb una cosa més greu, amb el seu passat que és definitivament allà, que hom no pot modificar, com a mínim nosaltres que vivim una vida que no dóna segones oportunitats. Un personatge literari com aquest agrimensor narrador, marxant d'un lloc a l'altre sense parar, explicant la seva historia a qualsevol que el vulgui escoltar, ens recorda dolorosament la presó temporal en la qual estem tancats també nosaltres. El futur és incert i el passat definitiu.

L'agrimensor no té cap possibilitat de modificar allò que ha estat la seva vida, però sí que té dret a jugar un joc que comença en la infantesa i acompanya qualsevol persona humana durant tota la seva vida (Freud, 1969: 167-179). El joc d'instaurar móns alternatius, de posar a l'escenari les possibilitats que no han ocorregut, però que d'alguna manera o altra haurien pogut formar part de la nostra vida. És la il-lusió que per alguns instants viurem una vida diferent. 
Fem doncs un salt en el conte que estem analitzant i intentem acostar-nos-hi amb aquesta hipòtesi. No és gens fàcil dir a partir d'on el narrador comença a somiar despert, a instaurar possibilitats alternatives. Caminem sobre una capa molt prima de gel que es trenca a mesura que hi anem passant per sobre. És evident que l'episodi del miratge ens sembla sospitós, coses així no acostumen a passar... Però, la vida idíl-lica en la caseta de fusta, té potser alguna garantia de veracitat més gran? No podem oblidar que tant l'episodi dels fenòmens sobrenaturals com la imatge pastoral són productes que sorgeixen del relat d'un home que s'ha presentat als seus companys de viatge com a agrimensor i que «ara» conta a uns oients o lectors suposadament presents la seva vida passada. I si s'ho està inventant tot? Mirem només com explica l'agrimensor viatjant el curs de la seva vida feliç (Calders, 1983: 24). A ningú no se li pot escapar el to irònic de l'agrimensor. Una vida així és simplement massa perfecta i l'entusiasme amb el qual la dibuixa és exagerat. La vida que transcorre com una cinta d'amics i la Providència que vetlla perquè totes les coses s'esdevinguin de la millor manera possible. La Providència? Si més no, després de llegir aquesta paraula, ens posem en alerta: no serà com si aquest noi assegut a l'autobús entre un home vell i el viatjant de comerç ens hagi picat l'ullet dient: «Ja ens entenem, oi? Jo faig veure que ho dic seriosament perquè puc comptar que tu ja entendràs que una vida així seria una presó, una gàbia d'or, un avorriment insuportable».

Mirant així, la casa fantasma seria només una pinzellada de color que permetria amanir la història i captar l'atenció dels oients. Qui es pot permetre d'inventar una caseta de fusta posada en una vall idíl-lica també pot fer que els desigs la facin moure.

Abans de començar el seu relat l'agrimensor viatjant li diu a l'home vell: «Escolteu: tinc ganes d'explicar-vos un episodi... Anava a dir un fet de la vida real, però em fa por que a vós no us ho semblarà, com als altres.» Aquesta advertència és simplement una estratègia retòrica? És simplement un recurs utilitzat per persuadir el públic que es cregui el relat encara que els fets no semblin gaire versemblants? També podria ser. Però, és clar, tampoc no tenim cap certesa que l'agrimensor viatjant, l'home vell i el comerciant existeixin. D'ells en sabem algunes coses perquè el narrador ens ho ha explicat. I on està situat aquest narrador?

Em produeix una tendresa molt gran imaginar-me'l assegut en una cruillla solitària de camins, sense saber quin camí ha de prendre un cop acabat el recorregut amb l'autobús. Per superar aquest mal pas s'inventa la història d'un home que ja hi va passar, per aquesta situació i la conta a uns oients imaginaris en veu alta, trencant el silenci.

Què hi podríem guanyar, els lectors, escoltant aquesta història? Es podria dir que els lectors potencials d'un llibre són innombrables (Calders, 1986: 12) i guarden en la memòria tantes coses que res de nou els podria ser explicat. Per això poden ser escèptics com l'home vell al principi del conte que fa a l'agrimensor la mateixa pregunta quan aquest es proposa d'explicar-li la seva història: «Què hi podríem guanyar?» A ell i a nosaltres l'agrimensor pot respondre amb la mateixa frase: «No ho sé. Potser un consell...» Un consell, potser sí. Però quin? Té res a veure amb les últimes paraules del vell: «Un poeta acceptaria allò demanat i obtingut de l'estrella, i la casa a mig camí hauria estat casa seva, amb eliminació de tota altra. Un home de preparació científica, per exemple, sigui el que sigui allò on sap que ha d'ésser, al capdavall dels quilòmetres que calguin. D'acord amb aquestes reflexions, podeu multiplicar exemples i triar» (Calders, 1983: 32).

Aquest consell del vell, que demanava l'agrimensor al principi del conte, dóna peu a pensar que la narració reflexiona sobre el mateix problema que tant magistralment ex- 
plora Thomas Mann en moltes de les seves obres, però sobretot en el seu conte Tonio Kröger (Mann, 1989: 103-165). Tonio, el protagonista d'aquesta narració, que viu en una ciutat del nord d'Alemanya, té un nom estranger i els cabells foscos. S'ha de fer lloc en una comunitat de nois i noies rossos, alts i d'ulls blaus. És una oposició que en aquest relat pren dimensions simbòliques. Per molt que s'esforci no aconsegueix l'amistat de les dues persones que més admira, Hans Hansen i Ingeborg Holm que per ell són l'encarnació de tot allò que justifica i dóna sentit a la vida. Aquests dos segurament no es deixarien molestar per l'aparició sobtada d'una casa fantasma com ho va fer el nostre agrimensor perquè Hans i Ingeborg viuen i desconeixen el dubte. A la mesura que Tonio es fa gran, la seva vida cada cop s'allunya més de la comunitat en la qual va créixer, finalment es trasllada a viure al sud i dedica tots els seus esforços a l'escriptura. Però en les seves converses amb una pintora exiliada sorgeix amb insistència el mateix tema, com guanyarse el reconeixement d'aquelles persones que són com els seus antics companys d'escola, de persones que no senten cap necessitat d'enterbolir la seva feliç existència. «La literatura no és cap professió, és una fugida, una fugida que comença en una edat molt tendre», li diu. I així Tonio, que es descriu com algú que els artistes anomenen burgès i els burgesos es neguen a acceptar decideix fer un viatge a la seva ciutat natal i d'allà més cap al nord, fins a Dinamarca, per veure si podrà trobar la vida que tan enyora. A Helsingör, un lloc de vacances a la costa danesa, torna a veure Hans i Ingeborg. Els dos formen part d'un grup nombrós de gent que han vingut a passar un dia a la natura i fer un ball al vespre. Tonio els observa des d'un balcó fosc i a través de les vidrieres segueix el ball en la sala il-luminada. La seva posició és privilegiada i li permet veure-ho tot i al mateix temps ser conscient que no forma part d'aquesta escena feliç, que no podrà mai formar part d'ella perquè és massa conscient de les coses per deixar-se endur pel corrent com si res. Tonio té l'ànima de poeta $\mathrm{i}$ amb això un senyal inesborrable imprès al front: mai podrà deixar de dubtar, de preguntar-se on és el seu lloc, encara que la seva més profunda admiració és dedicada precisament a tot allò que és humà, viu, ordinari. Tonio admira la vida idíl-lica dels nois i noies alts, rossos, d'ulls blaus, com aquells que deuen habitar també la vall verda en les propietats del gran terratinent en el conte de Pere Calders.

Això vol dir que l'home vell de l'autobús també li podria dir a Tonio Kröger el mateix que va dir-li a l'agrimensor: «Els joves viviu en una mena de plat de poc fons i tot va bé perquè us hi ofegueu» (Calders, 1983: 32). És evident que el vell no els entén, aquests joves que no en tenen prou amb fer castells en els núvols i considerar-se poetes o viure una vida en la qual no pot penetrar cap cosa extraordinària, en el cas que es vulguin afegir als homes que només obeeixen la raó. El vell no entén que hi ha persones per a les quals el dubte envers tot el que els envolta és la condició de la seva existència.

Per això el conte no acaba pas amb el consell que s'ha de saber sempre què vols per anar bé per la vida i està lluny de ser un pamflet que alerta sobre el perill de la indecisió. Hi ha una petita escena final, un cop acabat el viatge amb l'autobús, l'agrimensor s'asseu a la cruilla i espera. Encara que les seves mans no estiguin tacades de sang, que no tingui els ulls embenats i que les seves accions no havien produït cap mal físic, la circumstància que es trobi tot sol davant un encreuament de camins l'emparenta amb el rei Ėdip. Però el fet que no sigui un rei potser el fa encara més pròxim a nosaltres. S'ha quedat amb les mans buides. No té res encara que ho hagi intentat de valent. Ho ha intentat $i$ ha treballat per fer-ho tot tan bé com li era possible. Però ha actuat inadequadament, no s'ha sabut amotllar a les regles del món en el qual es trobava. 
Difícilment podria haver evitat el seu error. Quan el món es regia per les regles màgiques en aquella nit d'estiu abans de la festa (festa que permet des de l'antiguitat sortir del corrent temporal i entrar en una altra dimensió) ell creia que encara es trobava en el món ideal on tot era controlable. S'ha espantat i ha arrencat a córrer i amb això els ha perdut tots dos, el món ideal i el món màgic que ha sorgit del no-res una nit festiva. Tots dos perduts, igual que «ara» li és inaccessible també el tercer món, poblat de personatges que el podrien haver jutjat o li podrien haver donat algun consell. L'autobús ja ha partit, els companys de viatge tampoc ja no hi són.

En definitiva, el que el narrador espera quan ens explica la seva història és que el jutgem, que li perdonem els errors passats i li oferim una possibilitat de salvació. Potser fins i tot estaria disposat a buidar-se els ulls, seguint l'exemple d'Ėdip, si això fos la garantia per trobar la terra ferma sota els peus i un sol camí a seguir. Però, escapar i trobar el camí correcte en un món fragmentat és del tot il-lusori.

Sabem del cert que totes les seves accions han estat equivocades, però la situació del protagonista tanmateix no es resol d'una manera definitiva. No hi ha cap desenllaç, el conte arriba al final, però el temps continua corrent, no s'atura com en les grans obres tràgiques. L'agrimensor haurà de continuar vivint sabent que ha perdut el lloc on havia tingut intenció de desenvolupar la seva vida, que ha perdut la llar, la dona. Per això al final les mans del narrador acaronen un camafeu que li crema els palmells, forçant-lo a no oblidar mai.

El camafeu representa la penyora d'un amor, d'un amor perdut per sempre més. El camafeu és com un d'aquells objectes fantàstics que en la narració de Jorge Luis Borges Tlön, Uqbar, Orbis Tertius (Borges, 1989: 431-443) entren en la realitat des del més enllà. Vénen d'un món al qual no hi tenim accés com a proves que aquest lloc per nosaltres inaccessible realment existeix. Però aquests objectes no es barregen amb les coses que els envolten, floten a la superfície de la nostra realitat com taques d'oli, són visibles. Els hrön de Borges són objectes hipotètics, un model que permet exhaurir totes les possibilitats. Funcionen com el fesol blanc extret del sac en el qual crèiem tenir només fesols negres, perquè fins aleshores tots els fesols extrets eren negres. ${ }^{6}$ El fesol blanc ens força a adonar-nos que tot el nostre coneixement és inductiu, que esperem que allò que ja ha passat tornarà a passar, per poder així estipular-ne una regla a partir dels exemples. Borges ens recorda amb els seus objectes com és de fràgil allò que creiem ferm i conegut. Els hrön són la prova que res no ens pot garantir que demà el sol tornarà a sortir.

El camafeu en les mans d'un viatjant no té res de fantàstic, és un objecte visible, és una joia que crida l'atenció i també és l'única prova que el món del qual parlava el viatjant existeix. Nosaltres podem creure el seu relat perquè sabem que els móns perduts existeixen: cadascú de nosaltres guarda gelosament algun d'aquests camafeus màgics que ens obren records d'allà on els nostres peus ja no hi poden accedir. Les ciutats desig, les Fedores de possibilitats pensades, es clouen amb tapadores impenetrables: les podem veure, però no hi podem entrar per modificar-les. El passat de totes les persones és igualment inaccessible com ho són per al nostre protagonista la caseta de fusta i la dona a la qual pertany el camafeu. Si hi volguéssim trobar l'accés ens trobaríem condemnats al fracàs, com ens testimonia l'esforç d'un altre agrimensor, l'esforç del Landvermesser de Franz Kafka, que va creure que podria arribar fins al castell. De móns, en podem constru-

\footnotetext{
${ }^{6}$ Aquest és l'exemple de Charles Sanders Peirce que Umberto Eco cita amb insistència. Està molt ben explicat, per exemple, en l'assaig «L'abducció a Uqbar», Eco, 1987: 215-229.
} 
ir molts, però: «Quina altra cosa podria ésser en el fons, que ens pogués assegurar una tria afortunada?» (Calders, 1983: 32)

\section{La frontera}

Els personatges literaris són construïts només de paraules. Però per comprendre totes les dimensions d'aquest conte hem de franquejar l'última frontera, la frontera entre el text i el seu autor. Amb les paraules prestades d'Umberto Eco he dit al principi que no té gaire sentit preguntar-se si podríem trobar l'ànec Donald passejant pel Passeig de Gràcia. No hi ha dubte, però, que només uns decennis enrere hi hauria força possibilitats que en aquest carrer cèntric de Barcelona topéssim amb Pere Calders personalment. El conte Entre la ratlla i el desig és un dels seus textos més autobiogràfics. En aquest conte troben l'eco literari dels esdeveniments que han marcat profundament la vida de l'escriptor. Resumir-los representa l'epíleg necessari de la lectura del conte. Per elaborar el seu text Calders comptava amb unes vivències que li van permetre omplir la narració amb sentiments i reflexions que són lluny de qualsevol simulacre.

El 1935 Pere Calders es va casar amb Mercè Casals i un any més tard va néixer el seu primer fill, Joan. L'inici d'una feliç vida familiar va gairebé coincidir, doncs, amb la insurrecció de Mola i Franco. En començar la Guerra Civil no es va incorporar a files perquè havia estat descartat del servei militar. Però la targeta d'inutilitat no va impedir que es presentés l'octubre de 1937 com a voluntari per entrar al cos de Carrabiners. Va esdevenir sergent cartògraf $\mathrm{i}$ amb aquesta formació ensenyaria a llegir mapes als oficials. Llavors, el dia 10 de febrer de 1939, va rebre l'ordre de destruir el material topogràfic i les cartes militars, va pujar al coll d'Ares i va passar la frontera. El camp de refugiats situat a Prats de Molló va ser la seva primera destinació.

En el conte el narrador resumeix aquesta situació gairebé amb un proverbi: «És curiós observar amb quina frequiència la felicitat més perfecta precedeix els mals moments» (Calders, 1983: 25). A part de mostrar-se un mestre en transformar la vida en un univers literari, Calders ha sabut documentar el punt d'inflexió de la seva vida, el pas d'una frontera gens imaginària, per donar a conèixer tota la dimensió de les circumstàncies que l'han sobrevingut:

Caminem amb el cap cot, en silenci, amb el pensament ple de totes les coses que deixem darrera nostre. Quatre anys abans, en una excursió de vacances, jo havia recorregut aquest mateix indret amb una colla d'amics; era una de les èpoques millors de la meva vida i em sentia plenament feliç, tenia en vies de realització una de les ambicions que m'estimava més i estava a punt de casar-me. Amb la meva dona, dibuixant com jo, projectàvem els mobles de casa nostra i fèiem construir a gust nostre; sentíem tan aferrat el benestar que ens semblava que no hi havia res al món que pogués desfer-lo. I en el transcurs de quatre anys m'havia casat, havia tingut un fill, havia viscut la revolta militar i conegut la guerra i la desfeta. Em veig obligat a fugir de tot el que estimo i tinc tanta ràbia i tanta pena que ploro amb els ulls ben secs i no em doldria gens morir-me (Calders, 1939: 69).

En 1947, quan Calders publica el conte «Entre la ratlla i el desig», encara falten vuit anys perquè s'editi a Barcelona Cròniques de la veritat oculta, el primer llibre que permetria pensar que algun dia recuperaria en l'àmbit literari l'empenta que l'havia ca- 
racteritzat en els dies de la República. En una carta al seu pare que data del 1952 reconeixia que era precisament aquest el conte en el qual «es dibuixa el canvi». Els primers quinze anys del seu exili Calders no va publicar cap llibre, tot i que es feia conèixer amb els seus contes en totes les revistes catalanes que es van publicar a l'Amèrica Llatina i a França. Es tractava de publicacions en tiratges molt limitats i en llocs dispersos de manera que la seva obra quedava poc coneguda. Si al principi això no el va preocupar gaire, va ser just amb la gènesi de la narració «Entre la ratlla i el desig» que madura la decisió de tenir reunits els contes en un volum.

Però per arribar a veure publicat el seu primer llibre de la postguerra, l'escriptor va haver de passar no només pels camps de refugiats francesos, pujar al vapor Mexique, desembarcar en el port de Veracruz i viure la separació de la seva dona que arribaria a Mèxic molt més tard que ell, confiant el fill a la cura dels avis paterns a Barcelona. Amb l'exili es va fer evident el distanciament de la parella. Calders s'havia enamorat de Rosa Artís, germana del seu amic Avel-lí Artís Gener amb qui van emprendre junts l'aventura americana. El mateix dia de juliol del 1943 en què va obtenir el divorci, es va casar amb la Rosa. Li donarà tres fills i restarà la seva companya fins al final de la vida.

És comprensible que en un conte escrit el 1947 l'agrimensor s'hagi parat en una cruilla de camins ple de dubtes sobre si ha pres la direcció correcta. Avui està clar que s'havia encaminat cap a una fructífera empresa literària. La decisió de l'agrimensor de convertir-se en un incansable narrador de les peripècies de la pròpia vida va ser encertada, no només en els límits del conte, sinó també per a l'autor que ens ha deixat aquest testimoniatge de la seva estima per tot allò que no ha pogut retenir i de la seva angoixa davant les incerteses del futur.

\section{BIBLIOGRAFÍA}

Albaladejo, Tomás (1992/1996): La ficción realista y la ley de máximos semánticos. A: Sullà, Enric (ed.): Teoría de la novela. Antología de textos del siglo. Barcelona, 297-304.

Bioy Casares, Adolfo (1994): Memorias. Barcelona: Tusquets.

Borges, Jorge Luis (1944): Funes el memorioso. A: Artifícios (1944/1989). A: Obras completas. Barcelona: Emecé, 485-490.

Borges, Jorge Luis (1940): Tlön, Uqbar, Orbis Tertius. A: El jardín de senderos que se bifurcan (1941/1989). A: Obras completas. Barcelona: Emecé, 431-443.

Calders, Pere (1939): «Pàgines de l'exili. Prats de Molló». A: Revista dels Catalans d'Amèrica, 2 , 69-75.

Calders, Pere (1949): La ratlla i el desig. A: Les cròniques de la veritat oculta (1954/1983).

Barcelona: Edicions 62, 23-32 (Les millors obres de la literatura catalana).

Calders, Pere (1986): Ronda naval sota la boira. Barcelona: Edicions 62.

Calders, Pere: Els miralls de la ficció. Catàleg de l'exposició. Barcelona, CCCB, del 27-10-2000 al 28-1-2001.

Calvino, Italo (1972/1985): Les ciutats invisibles. Barcelona: Empúries (Narrativa 30).

Doležel, Ljubomir (1997): Mímesis y mundos posibles A: Garrigo Domínguez, Antonio (ed.). Teorías de la ficción literaria. Madrid: Arco libros.

Eco, Umberto (1987): Dels miralls i altres assaigs. Barcelona: Destino.

Eco, Umberto (1990): Els límits de la interpretació. Barcelona: Destino. 
Freud, Sigmund (1908/1969): Der Dichter und das Phantasieren. A: Freud, Sigmund: Studienausgabe. Band X. Bildende Kunst und Literatur. Frankfurt am Main: Fischer, 167-179.

Iser, Wolfang (1997): La ficcionalización. A: Garrigo Domínguez, Antonio (ed.): Teorías de la ficción literaria. Madrid: Arco libros.

Kafka, Franz (1926/1994): Das Schloß. Frankfurt am Main: Fischer Taschenbuchverlag.

Kafka, Franz (1915/1994): Die Verwandlung. A: Ein Landartzt und andere Drucke zu Lebzeiten. Frankfurt am Main: Fischer Taschenbuchverlag.

Mann, Thomas (1903/1989): Tonio Kröger. A: Der Tod in Venedig. Erzählungen. Frankfurt am Main: Fischer, 103-166.

Martínez-Bonati, Félix (1972): La estructura de la obra literaria. Barcelona: Seix Barral.

Martínez-Bonati, Félix (1992): La ficción narrativa (su lógica y ontología). Murcia: Universidad de Murcia.

Mukařovski, Jan (1977): Escritos de estética y semiótica del arte. Barcelona: Editorial Gustavo Gili.

Peirce, Charles, Sanders (1987): Obra lógico semiótica. Madrid: Taurus.

Schmidt, Siegfried J. (1997): La auténtica ficción es que la realidad existe. Modelo constructivista de la realidad, la ficción y la literatura. A: Garrido Domínguez, Antonio (ed.). Teorías de la ficción literaria. Madrid: Arco libros.

\section{IZGUBLJENE MOŽNOSTI: PERE CALDERS, SLED ŽELJE}

Caldersova zgodba Sled želje je pripoved o potovanju z avtobusom, med katerim neki moški nedoločne starosti sopotnikom razlaga o dogodivščinah iz svojega življenja. Bralec ima vtis, da je pred eno samo zgodbo. Le težko bo podvomil, da temu ni tako, saj je enotnost pripovedi zagotovljena s tisto značilnostjo, ki je nikoli ne postavimo pod vprašaj: z osebno identiteto. Prvoosebni pripovedovalec namreč govori o dogodkih, v katerih je on sam glavni junak. Toda zavedati se moramo, da je pripoved organizirana na različnih časovnih plasteh. Pripovedovalec, ki govori iz besedila in bralec, ki ga posluša, seveda skupaj stanujeta na istem sloju. Na naslednji stopnji naletimo na zemljemerca $\mathrm{v}$ avtobusu in na njegove sopotnike, ki govorijo z njim o tem in onem ter z zanimanjem prisluhnejo njegovi zgodbi. Ta zgodba pa se nahaja še eno plast niže, kjer bivajo zemljemerec, ko je še bil zemljemerec, lastnik posesti, drugi delavci, njegova žena, pa tudi hiša in konji, ki prav tako sodelujejo pri dokončni izgradnji tega sveta. Ravno tu je past, ki nam jo je pisatelj spretno nastavil: verjamemo, da smo pred istim zemljemercem »zdaj«, na avtobusu in na mogočni posesti. Calders s svojo zgodbo odkriva, kaj je tisto, kar nas najbolj omejuje kot človeška bitja, nedostopnost nas samih. To je razlog, da zemljemerec ne ve, ali je prava tista hiša, ki stoji na običajnem mestu ali ona druga, ki se je nenadoma pojavila tik pred njim. Prihodnost je negotova in preteklost dokončna. Ne v eno ne v drugo ne moremo vstopiti. Toda hkrati se moramo zavedati tudi, da se za nenavadnimi dogodki, o katerih pripoveduje zemljemerec, skriva boleča pisateljeva izkušnja, povezana s triindvajset let dolgim pregnanstvom v Mehiki. 